\title{
Improvement Production of Hyaluronic Acid by Streptococcus zooepidemicus in Sugarcane Molasses
}

\author{
Nicole Caldas Pan $^{1} \cdot$ Hanny Cristina Braga Pereira ${ }^{1}$. \\ Maria de Lourdes Corradi da Silva ${ }^{2}$. \\ Ana Flora Dalberto Vasconcelos ${ }^{2}$. \\ Maria Antonia Pedrine Colabone Celligoi ${ }^{1}$
}

Received: 8 September 2016 / Accepted: 3 November 2016/

Published online: 30 November 2016

(C) Springer Science+Business Media New York 2016

\begin{abstract}
Microbial hyaluronic acid (HA) production has been preferred rather than extraction from animal tissue for medical and cosmetic applications. In this context, to obtain an economically competitive HA production by Streptococcus zooepidemicus, culture conditions were studied to improve the polymer production in sugarcane molasses. The highest HA production by S. zooepidemicus ATCC 39920 achieved was $2.825{\mathrm{~g} . ~ \mathrm{~L}^{-1}}^{-1}$ a $4.5 \mathrm{~L}$ bioreactor with controlled $\mathrm{pH}$ (8.0) and medium containing molasses (85.35 g.. $\mathrm{L}^{-1}$ total sugar) pretreated with activated charcoal and yeast extract $\left(50\right.$ g. $\left.\mathrm{L}^{-1}\right)$. The HA produced exhibited a high molecular weight of $1.35 \times 10^{3} \mathrm{kDa}$ and the DPPH radical scavenging activity of the polymer at $1 \mathrm{~g} . \mathrm{L}^{-1}$ was $41 \%$. The FTIR and UV-Vis spectra showed no substantial differences in the spectral pattern between
\end{abstract}

Maria Antonia Pedrine Colabone Celligoi

macelligoi@uel.br

Nicole Caldas Pan

nicolepan@uel.br

Hanny Cristina Braga Pereira

hannypereira@uel.br

Maria de Lourdes Corradi da Silva

corradi@fct.unesp.br

Ana Flora Dalberto Vasconcelos

anaflora@fct.unesp.br

1 Departamento de Bioquímica e Biotecnologia, Universidade Estadual de Londrina - UEL, Rodovia Celso Garcia Cid - Pr 445 Km 380, Campus Universitário, Caixa Postal 10.011, Londrina, PR CEP 86.057-970, Brazil

2 Departamento de Química e Bioquímica, Faculdade de Ciências e Tecnologia, Universidade Estadual Paulista-UNESP, Rua Roberto Simonsen, n. 305, Presidente Prudente, São Paulo CEP 19060-900, Brazil 
produced and standard HA. This study is a promising strategy for sugarcane molasses application by producing high value-added products such as hyaluronic acid.

Keywords Hyaluronic acid · Sugarcane molasses · Streptococcus · Fermentation · Bioreactor

\section{Introduction}

Hyaluronic acid (HA) is a linear polysaccharide composed of disaccharide units of $(1,4)-\beta$ linked glucuronic acid and (1,3)- $\beta$-linked N-acetylglucosamine [1]. Due to its unique physicochemical properties, such as high intrinsic viscosity, antioxidant properties, chain stiffness and water-holding capacity [2], HA has been used for a wide variety of medical applications, including osteoarthritis [3, 4], ophthalmic surgery [5, 6] and cutaneous wound healing [7, 8]. In dermatology and cosmetic practices, HA has been employed to help the skin regain elasticity, turgor and moisture [9, 10]. Depending on the applications, the values of HA products and derivatives range from US $\$ 2000$ to $\$ 60,000 \mathrm{Kg}^{-1}$ [11].

Traditionally, hyaluronic acid is chemically extracted from animal waste such as rooster combs or umbilical cords. However, these resources are limited and HA from these tissues is generally associated with proteoglycans and often contaminated with HA degrading enzymes that make isolation of high purity and high molecular weight HA very difficult and costly [12]. Furthermore, the risk of cross-species viral and infection agent has been pointed out when using animal-derived biochemicals for human therapeutics. Therefore, microbial production is gradually replacing extraction as the preferred HA source with lower production cost, more efficient purification, higher yield compared to animal sources and less environmental pollution [1]. Although great progress has been achieved in HA microbial production, the price of culture media reduces the commercial competiveness of this alternative, and thus it is necessary to find a low-cost substrate replacement to reduce production cost [13].

More than $80 \%$ of the production costs of microbial HA produced by Streptococcus (particularly S. equi subsp. zooepidemicus) are due to the fermentation medium [14]. Thus, one important goal of the fermentation process is to study a new cost-effective culture medium that can increase HA production. In most studies, glucose is used as the primary carbon source for HA production $[15,16]$. The possibility of using byproducts rich in carbon and other essential nutrients for microorganism growth in industry is underexplored. Vázquez et al. [14, 17] reported the successful use of marine peptones from fishing byproducts for hyaluronic acid production. Agricultural resource derivatives such as cashew apple juice, cheese whey, and soy protein were also studied [11, 18, 19]. For instance, Amado et al. [20] saved $70 \%$ of the nutrient cost by replacing commercial peptone with cheese whey during polymer production.

Brazil is the largest sugar producer and exporter in the world, with 2015/2016 harvests of 33,928 thousand tons [21]. Approximately 0.3 tons are discharged when one ton of sugar is processed [22]. It is estimated that around 10 million tons of sugarcane molasses are discharged annually, which makes this product an available raw material for fermentation processes. In the current market, glucose prices are approximately $\$ 0.39 \mathrm{Kg}^{-1}$, whereas sugarcane molasses is $\$ 0.1 \mathrm{~kg}^{-1}$ [23]. This raw material has previously been applied to polymer production, such as cellulose [24] welan gum [25], succinoglycan [26] and levan [27]. In our study, we confirmed that crude sugarcane molasses could also be used as a promising carbon source for HA production [18]. 
Sugarcane molasses contains approximately $50 \%(w / w)$ total sugar (primarily sucrose, fructose and glucose), suspended colloids, metal ions, vitamins and nitrogen compounds [23]. The suspended particles and complex structures cause heterogeneity in the medium and may affect the cell growth rate. Therefore, many molasses pretreatments have been proposed to prepare a unique molasses medium and improve microbial production [24, 25]. Another important aspect of the use of agro-industrial byproducts for high value aggregated molecule production is the optimization of the concentrations of these substrates [28].

The aims of the present study were to improve HA production by $S$. zooepidemicus ATCC 39920 in sugarcane molasses medium, characterize its structure and estimate the antioxidant activity. The main highlight of this study is the originality of the pretreated sugarcane molasses application for hyaluronic acid production by $S$. zooepidemicus.

\section{Material and Methods}

\section{Sugarcane Molasses}

Sugarcane molasses was obtained from the Alltech group (São Pedro do Ivaí, PR, Brazil) and contained $(\mathrm{w} / \mathrm{w}): 53 \%$ sucrose, $4 \%$ glucose, $5 \%$ fructose, $6.6 \%$ ash, $1.2 \%$ amino acids such as glutamic acid, aspartic acid and alanine, and $0.17 \%$ metal ions including sodium, aluminum, iron, nitride, phosphide and potassium. Sugars were analyzed by high-performance liquid chromatograph (HPLC) (Shimadzu RID-10A, Japan) coupled to a refractive index detector, with an Aminex Carbohydrate HPX-87C $(300 \times 7.8 \mathrm{~mm}$, Biorad) column at $80{ }^{\circ} \mathrm{C}$. The mobile phase was Milli-Q water at a $0.6 \mathrm{~mL} \cdot \mathrm{min}^{-1}$ flow rate. Ash content was determined in an oven at $550{ }^{\circ} \mathrm{C}$ during $24 \mathrm{~h}$. Amino acids and metal ions concentrations were provided by Alltech group. The sugarcane molasses (SM) was diluted to $15 \%(w / v)$ of the total sugar concentration [29] with distilled water and centrifuged at $9956 \mathrm{x} \mathrm{g}$ at $4{ }^{\circ} \mathrm{C}$ for $15 \mathrm{~min}$. To obtain pretreated sugarcane molasses (PSM), the molasses solution was treated with $12 \%(w / v)$ activated charcoal at $70{ }^{\circ} \mathrm{C}$ with constant stirring for $1 \mathrm{~h}$, centrifuged at $9956 \mathrm{~g}$ at $4{ }^{\circ} \mathrm{C}$ for $15 \mathrm{~min}$ and filtered (Whatman, $\mathrm{n}^{\circ}$ 1) [28].

\section{Microorganism and Medium}

Streptococcus equi subsp. zooepidemicus ATCC 39920 was obtained from the Brazilian Collection of Environmental and Industrial Microorganisms (CBMAI). The strain was maintained in glycerol stock at $-80{ }^{\circ} \mathrm{C}$ and cultured on brain heart infusion (BHI) agar plates at $37{ }^{\circ} \mathrm{C}$ for $24 \mathrm{~h}$. For the inoculum, colonies from the agar plates were transferred to $125 \mathrm{~mL}$ Erlenmeyer flasks containing $25 \mathrm{~mL}$ BHI medium for $24 \mathrm{~h}$. These cultures were used to inoculate $1 \mathrm{~L}$ Erlenmeyer flasks containing $200 \mathrm{~mL}$ BHI medium for $6 \mathrm{~h}$. The flasks were incubated at $37{ }^{\circ} \mathrm{C}$ in a reciprocal shaker under $150 \mathrm{rpm}$. The cell concentration was determined by measuring turbidimetry at $\lambda=600 \mathrm{~nm}$; for each fermentation, the inoculum was standardized to 0.2 g. $\mathrm{L}^{-1}$.

The fermentation media contained ( $\mathrm{g} . \mathrm{L}^{-1}$ ): yeast extract (YE) ranging from 14.65 to 85.35 ; SM or PSM ranging from 14.65 to 85.35 of the total sugar content [29]; $2.5 \mathrm{~K}_{2} \mathrm{HPO}_{4} ; 2.0 \mathrm{NaCl}$ and $1.5 \mathrm{MgSO}_{4}$. SM, PSM and $\mathrm{MgSO}_{4}$ were autoclaved separately. 


\section{Hyaluronic Acid Production}

\section{Effect of Sugarcane Molasses and Yeast Extract}

To investigate the effect of the molasses pretreatment, the first experiment was performed in a $125 \mathrm{~mL}$ Erlenmeyer flask containing $25 \mathrm{~mL}$ fermentation media with SM or PSM at a $30 \mathrm{~g} . \mathrm{L}^{-1}$ concentration total sugar and 30 g.L $\mathrm{L}^{-1}$ YE. The experiment was performed in quadruplicate, and the samples were collected at the initial and final fermentation. Because the molasses pretreatment increased polymer production, we investigated the effect of the PSM (14.6585.35 g. $\mathrm{L}^{-1}$ of the total sugar) and YE (14.65-85.35 g. $\mathrm{L}^{-1}$ ) concentrations using a central composite design (CCD) (Table 2). The CCD required 13 experiments with four factorial points, four axial points and five central points. The factor level choice was based on Pan et al. [30]. Samples were collected at the initial and final fermentation. Based on the CCD results, fermentation in triplicate was performed in a $1 \mathrm{~L}$ Erlenmeyer flask containing $200 \mathrm{~mL}$ fermentation medium with 85.35 g.L $\mathrm{L}^{-1}$ PSM and 50 g.L $\mathrm{L}^{-1}$ YE. Samples were collected every $2 \mathrm{~h}$ to study the HA production profile. All experiments were incubated at $37{ }^{\circ} \mathrm{C}$ with an initial $\mathrm{pH}$ of 8.0 and rotation at $100 \mathrm{rpm}$ for $24 \mathrm{~h}$.

\section{Effect of $\mathrm{pH}$ on the Bioreactor}

The $\mathrm{pH}$ control effect was evaluated under the HA production conditions optimized by CCD. Batch fermentation in a $4.5 \mathrm{~L}$ bioreactor (Tecnal, Brazil) containing $2 \mathrm{~L}$ fermentation medium with 85.35 g.L $\mathrm{L}^{-1} \mathrm{PSM}$ and 50 g.L $\mathrm{L}^{-1} \mathrm{YE}$ was performed at $8.0 \mathrm{pH}$ that was controlled by an 8 mol. $\mathrm{L}^{-1} \mathrm{NaOH}$ solution. This fermentation was compared to a batch reactor without $\mathrm{pH}$ control (initial pH 8.0). The temperature was maintained at $37^{\circ} \mathrm{C}$, the rotation at $100 \mathrm{rpm}$ and the aeration rate at $0.5 \mathrm{vvm}$. Samples were collected every $2 \mathrm{~h}$ for $24 \mathrm{~h}$.

\section{Biomass, Hyaluronic Acid, Organic Acids, Ethanol and Total Sugar Determination}

Fermentation samples were centrifuged at $9956 \mathrm{~g}$ for $15 \mathrm{~min}$. The biomass was determined by measuring the turbidimetry at $\lambda=600 \mathrm{~nm}$ and correlated to the biomass curve in $\mathrm{g} . \mathrm{L}^{-1}$. Total sugar concentration was determined from the supernatant sample according to methodology described by Dubois and co-workers [29]. For the HA, lactate, formate, acetate and ethanol quantifications, the culture supernatant samples were filtered $(0.45 \mu \mathrm{m}$ pore size, Millipore) and $20 \mu \mathrm{L}$ was injected into a HPLC instrument (Shimadzu Corporation, Kyoto, Japan). The HA evaluation was performed in an OHpak SB-806 M HQ $80 \times 300 \mathrm{~mm}$ column (Shodex, Japan) at $40{ }^{\circ} \mathrm{C}$ with a $0.1 \mathrm{M} \mathrm{NaNO}_{3}$ mobile phase and a $1 \mathrm{~mL} \cdot \mathrm{min}^{-1}$ flow rate. Lactate, acetate, formate and ethanol were evaluated using an Aminex $7.8 \times 300 \mathrm{~mm}$ HPX$87 \mathrm{H}$ organic acid column (Bio-Rad, CA, USA) at $60^{\circ} \mathrm{C}$; the mobile phase was composed of a 0.005 mol. $\mathrm{L}^{-1} \mathrm{H}_{2} \mathrm{SO}_{4}$ solution with a $0.7 \mathrm{~mL} \cdot \mathrm{min}^{-1}$ flow rate. The peak elution profile was monitored with a Shimadzu RID - 10A refractive index detector (Shimadzu Corporation, Kyoto, Japan).

\section{Hyaluronic Acid Characterization}

To characterize HA, the $24 \mathrm{~h}$ samples from the bioreactor with the controlled $\mathrm{pH}$ were centrifuged (9956 g, $15 \mathrm{~min}, 4^{\circ} \mathrm{C}$ ), and the cell-free supernatant was precipitated with 
ethanol at a 1.5:1 $(v / v)$ ratio of ethanol:supernatant at $4{ }^{\circ} \mathrm{C}$ for $1 \mathrm{~h}$. The HA was re-dissolved in a $0.15 \mathrm{~mol} . \mathrm{L}^{-1} \mathrm{NaCl}$ solution. Three precipitations were performed to increase the HA purity. Then, trichloroacetic acid $(1 \%)$ was added until the HA solution reached $\mathrm{pH} 2.0$ and was maintained for $1 \mathrm{~h}$ at $4{ }^{\circ} \mathrm{C}$. The solution was centrifuged at $7744 \mathrm{~g}$ at $4{ }^{\circ} \mathrm{C}$ for $30 \mathrm{~min}$. The supernatant was dialyzed for $48 \mathrm{~h}$ with six distilled water changes. The frozen dialysis product was lyophilized to characterize the structural and antioxidant properties of the produced HA. Sodium hyaluronate with a molecular weight of 1.5-1.8 $\times 10^{3} \mathrm{kDa}$ (Sigma-Aldrich, Brazil Ltd.) was used as the standard.

The HA homogeneity was determined by high performance steric exclusion chromatography (HPSEC) coupled to a refractive index (RI) detector model RID 10A. The chromatography system consisted of an HPLC pump (Model Shimadzu-10 AD), a manual injection valve (Shimadzu) fitted with a 200- $\mu$ L loop and Ultrahydrogel columns $(7.8 \times 300 \mathrm{~mm})$ arranged in series with different exclusion limit connected in order of decreasing pore size $7 \times 10^{6}, 4 \times 10^{5}$, $8 \times 10^{4}$ and $5 \times 10^{3}$ Da corresponding to Ultrahydrogel (Waters) 2000, 500, 250 and 120, respectively. The mobile phase was $0.1 \mathrm{M} \mathrm{NaNO}_{3}$ with sodium azide $(0.03 \%)$, and a $0.6 \mathrm{~mL} . \mathrm{min}^{-1}$ flow rate. Data analysis was performed using LC solution software (Shimadzu Corporation). A standard curve of dextran with MW of 2000, 1400, 670, 500, 410, and $266 \mathrm{kDa}$ was made to determine the HA apparent molecular weight.

Fourier transform infrared spectroscopy (FTIR) was recorded at wavelengths between 4000 and $400 \mathrm{~cm}^{-1}$ on an IR PRESTIGE-21 (Shimadzu, Kyoto, Japan) spectrophotometer. Thirtytwo scans at a $4 \mathrm{~cm}^{-1}$ resolution were averaged and referenced against air. The powdered samples were compressed into $\mathrm{KBr}$ disks to measure the FTIR.

The UV-Vis absorption spectrum was assessed using a UV-Vis recording spectrophotometer (Biochrom Libra s22) in the 190-450 nm range. Distilled water was used as a reference and to dilute HA samples.

Antioxidant activity was estimated using 2,2-diphenyl-1-picrylhydrazyl (DPPH) (SigmaAldrich Brazil Ltd.). Briefly, $300 \mu \mathrm{L} 0.1 \mathrm{mM}$ DPPH in ethanol was added to $1 \mathrm{~mL}$ sample in 0.2-1.0 g.L $\mathrm{L}^{-1}$ concentrations. The mixture was left to stand for $30 \mathrm{~min}$ at room temperature. The absorbance was measured at $517 \mathrm{~nm}$ against a blank (water instead of sample and ethanol instead of DPPH). The scavenging percentage activity was calculated as $(\%)=\left[1-\left(A_{1}-A_{2}\right) /\right.$ $\left.A_{0}\right] \times 100$, where $\mathrm{A}_{0}$ is the control absorbance (water instead of sample solution), $\mathrm{A}_{1}$ is the sample absorbance and $A_{2}$ is the sample absorbance under identical conditions as $A_{1}$ with ethanol instead of DPPH solution. Ascorbic acid (Sigma-Aldrich Brazil Ltd.) was used as a standard for the assay.

\section{Statistical Analysis}

The data analysis was performed using the Statistica 9.0 software (StatSoft Inc., USA). The averages were compared using the Tukey test at a $5 \%$ probability level $(p<0.05)$. For optimal point prediction, a second order polynomial function was fitted to the CCD experimental results:

$$
Y_{i}=b_{0}+\sum_{i} b_{i} x_{i}+\sum_{i} b_{i i} x_{i}^{2}+\sum_{i j} b_{i j} x_{i} x_{j}
$$

in which $Y_{\mathrm{i}}$ is the response, $x_{i} x_{j}$ are independent variables, $b_{0}$ is the offset term, is the $i$ th linear coefficient, $b_{i i}$ is the $i$ th quadratic coefficient, and $b_{i j}$ is the $i j$ th interaction 
coefficient. Analysis of variance (ANOVA) was used to estimate the statistical parameters. The fit quality of the polynomial model equation was expressed by the determination coefficient $\mathrm{R}^{2}$, and its statistical significance was assessed by the F-test.

\section{Results and Discussion}

\section{Hyaluronic Acid Production}

\section{Effect of Sugarcane Molasses Pretreatment}

Molasses and molasses pretreated with activated charcoal were evaluated as carbon sources for HA production. PSM increased HA production by $19 \%$ compared to SM (Table 1). This result suggested that activated charcoal pretreatment decreased the level of inhibition by factors such as excessive metal ions and raised the fermentation quality. Although sugarcane molasses generally contains essential nutrients beneficial to microorganism growth, it also has metal ions and suspended colloids, which may be detrimental to microorganisms because they influence the medium $\mathrm{pH}$ and inactivate enzymes associated with product biosynthesis [25]. The individual presence of $\mathrm{Na}^{+}$ and $\mathrm{Fe}^{2+}$ in medium containing glucose and yeast extract inhibited HA production by S. zooepidemicus ATCC 39920 [31]. Moreover, Tlapak-Simmons et al. [32] reported that hyaluronan synthase was sensitive to the concentrations of monovalent cations such as $\mathrm{Na}^{+}$and $\mathrm{K}^{+}$. This result complied with research on the production of bacterial cellulose [24], welan gum [25] and polyhydroxyalkanoates [33] that reported an increase in polymer production when crude molasses was replaced by pretreated molasses. The total sugar consumption was $8.839 \pm 0.297$ g.L $\mathrm{L}^{-1}$ in $\mathrm{SM}$ and $8.433 \pm 0.343$ g.L $\mathrm{L}^{-1}$ in PSM and these results did not show significant difference $(p>0.05)$. Acetate synthesis (Table 1) was also increased in PSM compared to SM, which confirmed the change in cellular metabolism in favor of polymer production. This finding was explained by Chong and Nielsen [34], who observed that extra ATP concurrently generated during acetate formation by acetate kinase facilitated HA production. Biomass and lactate synthesis were not significantly different in PSM and SM media. Thus, the pretreatment of molasses with activated charcoal was advantageous because the cost of this pretreatment was low and the product has a high aggregated value. Therefore, we used PSM for the subsequent experiments.

Table 1 Hyaluronic acid, biomass, lactate and acetate production by S. zooepidemicus ATCC 39920 in sugarcane molasses and pretreated sugarcane molasses

\begin{tabular}{|c|c|c|c|c|}
\hline Molasses & $\begin{array}{l}\text { Hyaluronic acid } \\
\text { g. } \mathrm{L}^{-1}\end{array}$ & $\begin{array}{l}\text { Biomass } \\
\text { g. } \mathrm{L}^{-1}\end{array}$ & $\begin{array}{l}\text { Lactate } \\
\text { g. } \mathrm{L}^{-1}\end{array}$ & $\begin{array}{l}\text { Acetate } \\
\text { g. } \mathrm{L}^{-1}\end{array}$ \\
\hline SM & $0.557 \pm 0.038^{b}$ & $2.178 \pm 0.133^{\mathrm{a}}$ & $4.021 \pm 0.229^{\mathrm{a}}$ & $0.582 \pm 0.031^{\mathrm{b}}$ \\
\hline PSM & $0.662 \pm 0.003^{\mathrm{a}}$ & $2.123 \pm 0.286^{\mathrm{a}}$ & $4.315 \pm 0.161^{\mathrm{a}}$ & $0.678 \pm 0.018^{\mathrm{a}}$ \\
\hline
\end{tabular}

SM - sugarcane molasses; PSM - pretreated sugarcane molasses. Different lower-case letters indicate significant differences at the $\alpha=0.05$ level in each column 


\section{Effect of Pretreated Sugarcane Molasses and Yeast Extract}

The PSM and YE concentrations were assessed by CCD to evaluate their effects on HA production, biomass, lactate and acetate synthesis (Table 2). Because molasses has a low total nitrogen content, supplementation with yeast extract is necessary to achieve an ideal carbon/nitrogen ratio. Lancefield group $\mathrm{A}$ and $\mathrm{C}$ streptococci bacteria require complex nutrients due to their limited ability to synthesize specific amino acids and vitamins [19, 35]. Previous studies suggested that certain essential amino acids cannot be synthesized from an inorganic nitrogen source, because hyaluronic acid production in this medium is very low [36, 37]. Other studies that evaluated different organic nitrogen sources demonstrated that the highest HA production was obtained using yeast extract [11, $18,37]$. The main contributions of yeast extract to hyaluronic acid production are purine, pyrimidine bases and vitamin B [38]. Therefore, yeast extract was the nitrogen source used in this research. The maximum observed HA production was 0.860 g. $\mathrm{L}^{-1}$ and was achieved in medium containing PSM with 85.35 g.L $\mathrm{L}^{-1}$ total sugar content and 50 g.L $\mathrm{L}^{-1}$ YE. HA production was $30 \%$ higher than the production level obtained in the previous experiment using PSM $\left(0.662 \mathrm{~g} . \mathrm{L}^{-1}\right)$ (Table 1). The effect estimated for each variable was also reported (Table 3). An increase in the PSM and YE concentrations from 25 to 75 g.L ${ }^{-1}$ led to an increase in the HA production of 0.106 and 0.108 g.L $\mathrm{L}^{-1}$, respectively. In contrast, the interaction between PSM and YE had a negative influence. This result supports the finding that agro-industrial byproducts have complex compositions in which a substrate can show an individual positive effect but have a negative effect in the overall system due to an

Table 2 Hyaluronic acid, biomass, lactate and acetate production by S. zooepidemicus ATCC 39920 at different pretreated sugarcane molasses and yeast extract concentrations

\begin{tabular}{|c|c|c|c|c|c|c|c|}
\hline \multirow[t]{3}{*}{ Run* } & \multicolumn{2}{|c|}{ Factor level } & \multicolumn{5}{|l|}{ Response } \\
\hline & \multirow[t]{2}{*}{$x_{1}$} & \multirow[t]{2}{*}{$x_{2}$} & \multirow{2}{*}{$\begin{array}{l}\text { Hyaluronic acid } \\
\left(\mathrm{g} . \mathrm{L}^{-1}\right)\end{array}$} & \multirow{2}{*}{$\begin{array}{l}\text { Biomass } \\
\left(\mathrm{g} \cdot \mathrm{L}^{-1}\right)\end{array}$} & \multicolumn{2}{|c|}{ Lactate } & \multirow{2}{*}{$\begin{array}{l}\text { Acetate } \\
\left(\text { g. } \mathrm{L}^{-1}\right)\end{array}$} \\
\hline & & & & & $\left(\mathrm{g} \cdot \mathrm{L}^{-1}\right)$ & & \\
\hline 1 & -1 & -1 & 0.555 & 2.304 & 4.256 & & 0.682 \\
\hline 2 & -1 & 1 & 0.759 & 2.891 & 9.096 & & 1.549 \\
\hline 3 & 1 & -1 & 0.749 & 2.529 & 4.796 & & 0.659 \\
\hline 4 & 1 & 1 & 0.758 & 2.634 & 8.692 & & 1.245 \\
\hline 5 & -1.41 & 0 & 0.695 & 2.749 & 5.991 & & 0.937 \\
\hline 6 & 1.41 & 0 & 0.860 & 2.720 & 7.166 & & 0.944 \\
\hline 7 & 0 & -1.41 & 0.623 & 2.261 & 4.378 & & 0.698 \\
\hline 8 & 0 & 1.41 & 0.776 & 2.933 & 9.172 & & 1.357 \\
\hline 9 & 0 & 0 & 0.809 & 2.760 & 7.329 & & 1.131 \\
\hline 10 & 0 & 0 & 0.796 & 2.566 & 7.549 & & 1.167 \\
\hline 11 & 0 & 0 & 0.766 & 2.677 & 6.898 & & 1.060 \\
\hline 12 & 0 & 0 & 0.775 & 2.607 & 6.968 & & 1.068 \\
\hline 13 & 0 & 0 & 0.767 & 2.772 & 7.094 & & 1.204 \\
\hline \multirow[t]{2}{*}{ Code } & \multirow{2}{*}{\multicolumn{2}{|c|}{ Variables }} & \multicolumn{5}{|c|}{ Coded variables levels } \\
\hline & & & -1.414 & -1 & 0 & +1 & +1.414 \\
\hline$\left(X_{1}\right)$ & \multicolumn{2}{|c|}{ PSM (total sugar g. $\mathrm{L}^{-1}$ ) } & 14.65 & 25 & 50 & 75 & 85.35 \\
\hline$\left(\mathrm{X}_{2}\right)$ & \multicolumn{2}{|c|}{$\mathrm{YE}\left(\mathrm{g} \cdot \mathrm{L}^{-1}\right)$} & 14.65 & 25 & 50 & 75 & 85.35 \\
\hline
\end{tabular}

(*)Assays were randomized; PSM - pretreated sugarcane molasses; YE - yeast extract 
Table 3 Effect estimates for hyaluronic acid production by S. zooepidemicus ATCC 3992 from the CCD

\begin{tabular}{lcccc}
\hline Factor & Effect & Std. Err. & $t$-value & $p$-value \\
\hline Average & 0.783 & 0.011 & 74.171 & $0.00000^{*}$ \\
PSM (L) & 0.106 & 0.017 & 6.366 & $0.00037^{*}$ \\
PSM (Q) & -0.022 & 0.018 & -1.221 & 0.26175 \\
YE (L) & 0.108 & 0.017 & 6.448 & $0.00035^{*}$ \\
YE (Q) & -0.100 & 0.018 & -5.574 & $0.00084^{*}$ \\
PSM YE & -0.098 & 0.024 & -4.138 & $0.00436^{*}$ \\
\hline
\end{tabular}

PSM - pretreated sugarcane molasses; YE - yeast extract. * Significant factors $(p<0.01)$

increment in the concentration of other constituents [28]. Only the PSM quadratic term was not significant $(p<0.01)$ for hyaluronic acid production at a $99 \%$ confidence level. These results showed the importance of the amounts of the PSM and YE variables for hyaluronic acid production. The effects of these variables in biomass, lactate and acetate synthesis were also evaluated to observe the carbon flux at the studied conditions. The total sugar consumption in the assays (Table 2) was $18.238 \pm 3.698 \%$ initial sugar concentration, except for assays 2 $(42.469 \%)$ and $5(49.630 \%)$. Of these metabolized carbons, 60-80\% was utilized for lactate production and 8-14\% for acetate. According to Chong and Nielsen [34] the HA and biomass synthesis account for 5-10\% of the carbon metabolized, whereas lactate and acetate are held responsible for the majority of the carbon. YE was the most significant variable for the biomass, lactate and acetate synthesis, with the YE linear term significant at $1 \%$ level of significance. The increase from $25 \mathrm{~g} . \mathrm{L}^{-1}$ to $75 \mathrm{~g} . \mathrm{L}^{-1} \mathrm{YE}$ caused an increase of $15 \%, 30 \%$ and $55 \%$ in the biomass, lactate and acetate concentrations, respectively. The effect of PSM was not significant for these responses and the interaction between YE and PSM was significant only for biomass, and its was effect negative. Equations 2-5 represent the coded models used for HA production, biomass, lactate and acetate synthesis.

$$
H A=0.775+0.053 \times P S M+0.054 \times Y E-0.048 \times Y E^{2}-0.049 \times P S M \times Y E
$$

$$
\begin{gathered}
\text { Biomass }=2.683+0.205 \times Y E-0.060 \times Y E^{2}-0.120 \times P S M \times Y E \\
\text { Lactate }=7.037-0.262 \times P S M^{2}+1.940 \times Y E
\end{gathered}
$$

$$
\text { Acetate }=1.100-0.076 \times P S M^{2}+0.298 \times Y E-0.070 \times P S M \times Y E
$$

ANOVA was used to evaluate the adequacy of the fitted model (Table 4). The determination coefficient $\left(\mathrm{R}^{2}\right)$ was $93.83 \%$ for HA production, $88.56 \%$ for biomass, $94.05 \%$ for lactate and $89.49 \%$ for acetate synthesis. According to Haaland [39], $\mathrm{R}^{2}$ values above $90 \%$ are considered very good for the experimental design of biotechnological processes. Based on the $F$ test, the models were predictive because $F$-calc was higher than $F$-tab. Furthermore, the pure error was very low and the lack of fit was not significant, indicating that the models were reproductive and adequately represented by the data in the experimental region. 
Table 4 Analysis of the variance (ANOVA) of hyaluronic acid, biomass, lactate and acetate production by S. zooepidemicus ATCC 39920 from the CCD

\begin{tabular}{|c|c|c|c|c|c|c|c|c|}
\hline Variance source & $\begin{array}{l}\text { Level } \\
\text { of freedom }\end{array}$ & $\begin{array}{l}\text { Sum } \\
\text { of Square }\end{array}$ & Mean Square & f-calc & f-tab & $\mathrm{R}^{2}$ & $\mathrm{R}_{\text {adj }}^{2}$ & $p$ - value \\
\hline \multicolumn{9}{|l|}{ Hyaluronic acid } \\
\hline Regression & 0.07185 & 4 & 0.01796 & 30.40 & 3.84 & 0.93828 & 0.90742 & \\
\hline Residue & 0.00473 & 8 & 0.00059 & & & & & \\
\hline Lack of fit & 0.00327 & 4 & 0.00082 & & & & & 0.22559 \\
\hline Pure error & 0.00145 & 4 & 0.00036 & 2.25 & 6.39 & & & \\
\hline Total & 0.07657 & 12 & - & & & & & \\
\hline \multicolumn{9}{|l|}{ Biomass } \\
\hline Regression & 0.42052 & 3 & 0.14017 & 23.21 & 3.86 & 0.88555 & 0.84740 & \\
\hline Residue & 0.05435 & 9 & 0.00604 & & & & & \\
\hline Lack of fit & 0.02132 & 5 & 0.00426 & 0.52 & 6.26 & & & 0.75731 \\
\hline Pure error & 0.03303 & 4 & 0.00826 & & & & & \\
\hline Total & 0.47487 & 12 & - & & & & & \\
\hline \multicolumn{9}{|l|}{ Lactate } \\
\hline Regression & 30.57855 & 2 & 15.28928 & 79.03 & 4.10 & 0.94050 & 0.92860 & \\
\hline Residue & 1.93463 & 10 & 0.19346 & & & & & \\
\hline Lack of fit & 1.64519 & 6 & 0.27420 & 3.79 & 6.16 & & & 0.10901 \\
\hline Pure error & 0.28943 & 4 & 0.07236 & & & & & \\
\hline Total & 32.51318 & 12 & - & & & & & \\
\hline \multicolumn{9}{|l|}{ Acetate } \\
\hline Regression & 0.77148 & 3 & 0.25716 & 25.56 & 3.86 & 0.89494 & 0.85993 & \\
\hline Residue & 0.09056 & 9 & 0.01006 & & & & & \\
\hline Lack of fit & 0.07499 & 5 & 0.01500 & 3.85 & 6.26 & & & 0.10781 \\
\hline Pure error & 0.01557 & 4 & 0.00389 & & & & & \\
\hline Total & 0.86204 & 12 & - & & & & & \\
\hline
\end{tabular}

The response surfaces were obtained using eqs. 2-5 (Fig. 1). The biomass concentration was enhanced by the increase in YE and decrease in PSM (Fig. 1b). This result is in accordance with the typical behavior of lactic acid bacteria, whose biosynthetic need is met by the complex nitrogen source. Organic nitrogen sources are considered essential for good Streptococci growth because there is evidence that these components also supply a large proportion of the carbon for cellular biosynthesis [40]. Several Streptococcus strains can only grow in media containing vitamins, purines and amino acids which are mainly used as carbon sources for the cell skeleton due to a lack of tricarboxylic acid cycle (TCA) and precursors for the synthesis of most amino acids and nucleotides [41]. The lactate and acetate concentrations were raised by the increase in YE (Fig. 1c,d), and 50 g.L ${ }^{-1}$ and 32 g.L. ${ }^{-1}$ of PSM were the best concentrations for the synthesis of these organic acids, respectively. Under the best condition observed for HA production (85.35 g.L $\mathrm{L}^{-1}$ PSM and 50 g.L ${ }^{-1} \mathrm{YE}$ ), the predicted value was 0.850 g.L ${ }^{-1}$ (Fig. 1a). To confirm the predicted results, experiments were performed in quintuplicate using these conditions, and a value of $0.842 \pm 0.025$ g. $\mathrm{L}^{-1}$ was obtained. The good correlation between these results $(p=0.50095)$ verifies the model validation for HA production. In these experiments, the total sugar consumption, biomass, lactate and acetate 
(a)

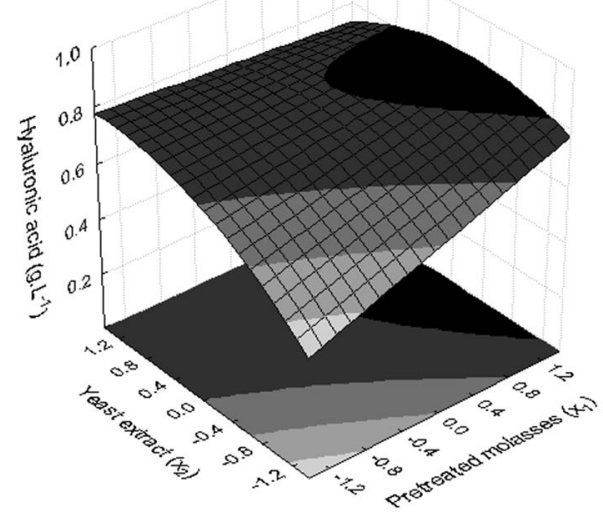

(c)

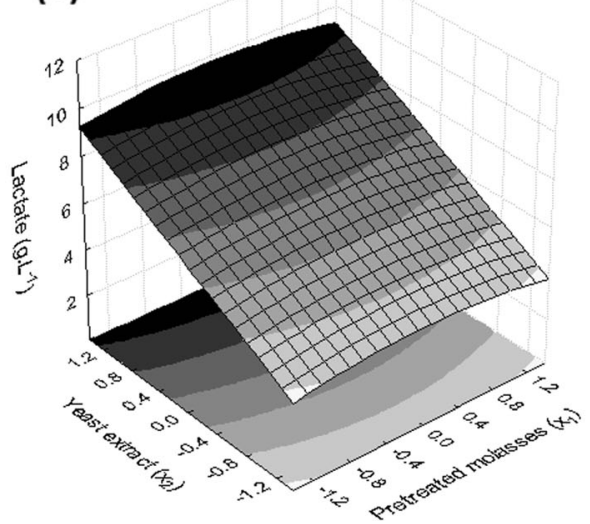

(b)

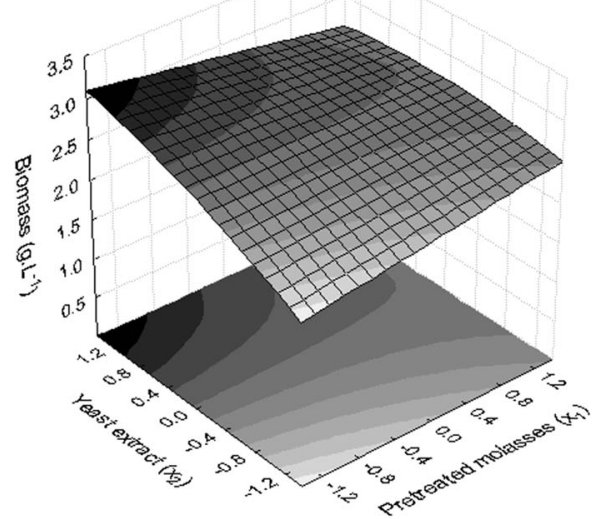

(d)

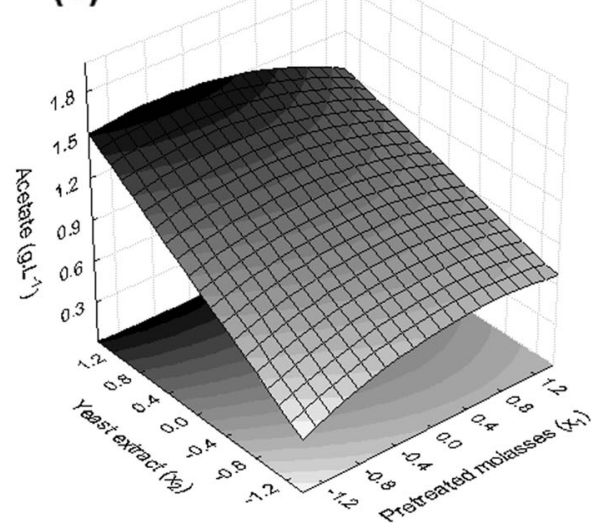

Fig. 1 Response surfaces of (a) hyaluronic acid, (b) biomass, (c) lactate and (d) acetate production by S. zooepidemicus ATCC 39920 in pretreated sugarcane molasses $\left(\times_{1}\right)$ and yeast extract $\left(\times_{2}\right)$

results were $9.375 \pm 0.598$ g.L $\mathrm{L}^{-1}, 2.398 \pm 0.054$ g.L $\mathrm{L}^{-1}, 5.682 \pm 0.639$ g.L $\mathrm{L}^{-1}$ and $0.706 \pm 0.053$ g.L $\mathrm{L}^{-1}$, respectively.

In the conditions optimized by CCD, medium containing PSM with 85.35 g.L $\mathrm{L}^{-1}$ total sugar content and 50 g.L $\mathrm{L}^{-1} \mathrm{YE}$, the assays were performed in $1 \mathrm{~L}$ Erlenmeyer flasks containing $200 \mathrm{~mL}$ medium to study the HA production profile. As shown in Fig. 2a, after $2 \mathrm{~h}$ of lag phase, cells began exponential growth until $6 \mathrm{~h}$ with a specific growth rate at $0.30 \pm 0.10 \mathrm{~h}^{-1}$ and biomass concentration reached $2.075 \pm 0.023 \mathrm{~g} . \mathrm{L}^{-1}$. The HA concentration followed the biomass synthesis trend and achieved a value of $0.825 \pm 0.075 \mathrm{~g} . \mathrm{L}^{-1}$ at $24 \mathrm{~h}$. This value was not significantly different compared to the result predicted in the model by CCD $(p=0.622210)$. The maximum lactate and acetate synthesis were $7.840 \pm 0.445 \mathrm{~g} . \mathrm{L}^{-1}$ at $24 \mathrm{~h}$ and $0.531 \pm 0.072 \mathrm{~g} . \mathrm{L}^{-1}$ at $14 \mathrm{~h}$, respectively, and the total sugar consumption at $24 \mathrm{~h}$ was $10.622 \pm 0.895$ g.L $\mathrm{L}^{-1}$.

Due to the lactate and acetate production, the final $\mathrm{pH}$ in the assays performed in Erlenmeyers ranged from 4.7 to 5.0. The decrease in $\mathrm{pH}$ which cannot be controlled in shake flasks may have caused inhibition of microbial growth and limited hyaluronic acid production. 
Fig. 2 Production of hyaluronic acid $(\square)$, biomass $(\diamond)$, lactate $(\Delta)$ and acetate $(\circ)$ by

S. zooepidemicus ATCC 39920 in (a) Erlenmeyer flask uncontrolled $\mathrm{pH}$, (b) bioreactor uncontrolled $\mathrm{pH}$ and (c) bioreactor with controlled $\mathrm{pH}$

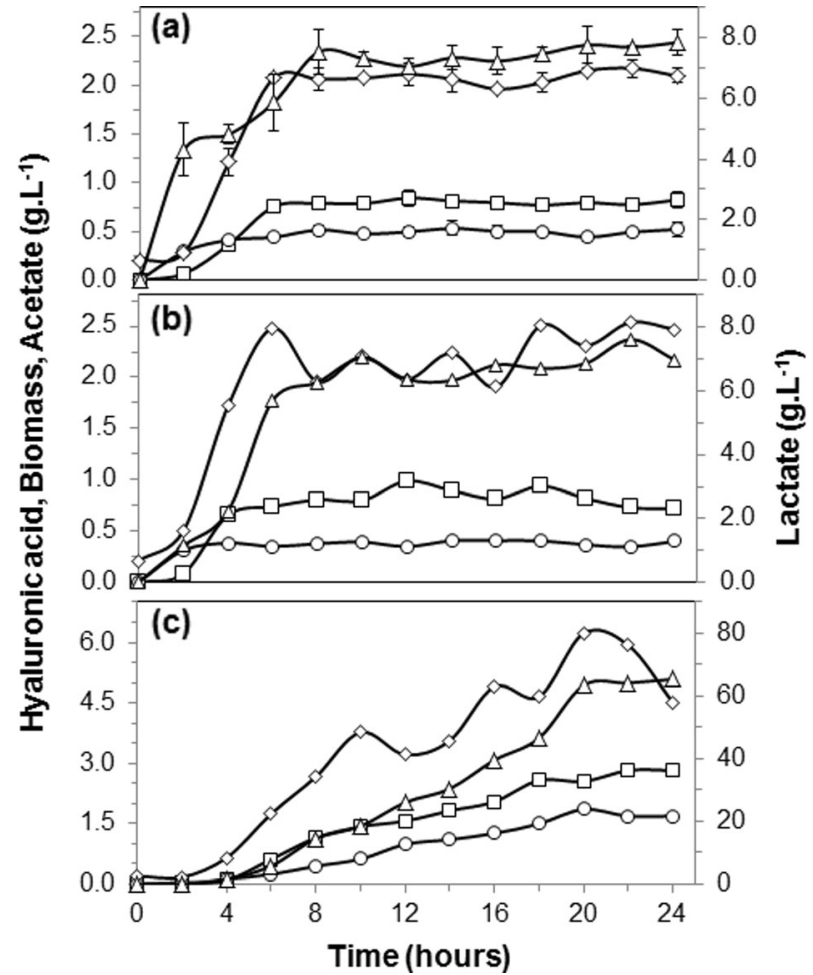

Then, fermentations in bioreactor were performed to evaluate the effect of $\mathrm{pH}$ control in optimized medium.

\section{Effect of $p H$ on the Bioreactor}

Pan et al. [30] investigated the effect of the initial $\mathrm{pH}$ on $S$. zooepidemicus fermentation in a shake flask and concluded an initial $\mathrm{pH}$ of 8.0 was best for HA production. Shake flasks have been widely used in both studies and biotechnology process optimization because they allow experiments to be conducted with minimal costs and materials. However, shake flasks have several limitations. For instance, some are unable to control the $\mathrm{pH}$ and the dependency of the oxygen transfer rate on the agitation speed. Therefore, scaling from shake flasks to bioreactors is essential to obtain large quantities of the final product [42]. The influence of controlled $\mathrm{pH}$ on HA production was evaluated in a bioreactor using medium optimized by CCD and 0.5 vvm aeration (Fig. 2c). A control experiment was run at initial $\mathrm{pH} 8.0$ that was not controlled (Fig. 2b). Under alkaline conditions, the maximum specific cell growth rate was $0.14 \mathrm{~h}^{-1}$ and the biomass concentration reached 6.22 g.L $\mathrm{L}^{-1}$, compared with $0.27 \mathrm{~h}^{-1}$ and 2.539 g.L $\mathrm{L}^{-1}$ in the control experiment, respectively. During fermentation without $\mathrm{pH}$ control, the $\mathrm{pH}$ decreased to 4.9 during the first $8 \mathrm{~h}$, which may have caused the inhibition of microbial growth. The $\mathrm{pH}$ reduction was caused mainly by lactate production. According to other studies, batch culture at $\mathrm{pH}$ less than 6.0 slowed cell growth and resulted in very low HA production [35, 43]. Diauxic growth was observed when the $\mathrm{pH}$ was controlled, suggesting the preferential utilization of the carbon sources present in PSM (predominantly sucrose and lower concentrations of fructose 
and glucose). The total sugar consumption in $\mathrm{pH}$ controlled medium was 75.754 g.L $\mathrm{L}^{-1}$ at $24 \mathrm{~h}$, which was 6.12-fold greater than in the control experiment. HA, lactate and acetate were produced in parallel with the biomass. Under controlled $\mathrm{pH}$ conditions, the maximum HA production was $2.825 \mathrm{~g} . \mathrm{L}^{-1}$ at $24 \mathrm{~h}$. This value was 2.86 -fold greater than the maximum HA production in uncontrolled $\mathrm{pH}$ conditions $\left(0.988 \mathrm{~g} . \mathrm{L}^{-1}\right.$ at $\left.12 \mathrm{~h}\right)$. The positive effect of intermittent alkaline-stress on HA production by $S$. zooepidemicus WSH-24 was reported by Liu et al. [44]. The authors suggested that the carbon flux was redirected, thereby increasing HA production by up to $30 \%$ and decreasing the biomass by $24 \%$. However, in our results the relationship between biomass and HA production was positive. This effect was also observed by Shah and co-workers [16]. Pires and Santana [15] explained that the high HA concentration in an alkaline medium might be due to the exposition of the microorganisms to the stress condition in which the cells produce the capsule as a way to shield themselves. Lactate and acetate synthesis increased to 65.368 and 1.855 g.L $\mathrm{L}^{-1}$ compared with 7.623 and 0.408 g.L $\mathrm{L}^{-1}$ in the control, respectively.

Formate and ethanol were not observed in any experiments in this research. The lack of formate synthesis suggested good aeration conditions in the experiments because pyruvate formate lyase is extremely sensitive to oxygen [34].

HA productions by $S$. zooepidemicus ATCC 39920 in bioreactor reported in previous studies ranges from 1 to 5 g.L $\mathrm{L}^{-1}$. The highest HA concentration observed by Pires and Santana [15] was 1.21 g.L $\mathrm{L}^{-1}$ in a medium containing glucose, yeast extract and salts. Lai et al. [36] reported that about $2.442 \mathrm{~g}$. $\mathrm{L}^{-1} \mathrm{HA}$ was synthesized at an optimal $\mathrm{C} / \mathrm{N}$ of 1.5:1 using glucose and a mixture of yeast extract and tryptone. The highest polymer productions were observed in media containing casein, 3.32 g.L $\mathrm{L}^{-1}$ [45] and 5.0 g.L $\mathrm{L}^{-1}$ [46], and media supplemented with amino acid, oxygen vector, and other additives that aimed to redirect the carbon flux to HA production. Adding $5 \mathrm{~g} . \mathrm{L}^{-1}$ glutamine and $25 \mu \mathrm{M}$ sodium iodoacetate increased the HA concentration to 5.0 g. $\mathrm{L}^{-1}$ from 2.0 g.L $\mathrm{L}^{-1}$ in a control run [16]. Lai et al. [47] studied the potential of oxygen vectors for enhancing HA biosynthesis and obtained a high production of 4.25 g. $\mathrm{L}^{-1}$ when $0.5 \%(v / v)$ n-hexadecane was added. These supplementations to the fermentation medium increase the production cost, and are not an advantage when the aim of study is to reduce the polymer price. Considering the studies that evaluated alternative fermentation media for hyaluronic acid production (Table 5), the concentration of $2.825 \mathrm{~g} . \mathrm{L}^{-1}$ polymer obtained in our study was high. These results point out the possibility of obtaining a high HA production by replacing the commercial sources with an inexpensive alternative, emphasizing the use of sugarcane molasses as a promising carbon source.

\section{Hyaluronic Acid Characterization}

The homogeneity of the hyaluronic acid produced by Streptococcus zooepidemicus in a bioreactor with the $\mathrm{pH}$ controlled at 8.0 was verified by HPSEC/RID. The chromatography profile showed a single symmetrical peak (Fig. 3b) with an enlarged base that most likely indicated a higher polydispersity (Mw/Mn 1.32) than the hyaluronic acid standard (Fig. 3a), which eluted in $36.7 \mathrm{~min}$ and had 1.5-1.8 $\times 10^{3} \mathrm{kDa}$ molecular weight. The hyaluronic acid molecular weight from $S$. zooepidemicus was $1.35 \times 10^{3} \mathrm{kDa}$, using dextrans of known molecular weight as standards. HA applications depend on its molecular weight, a high molecular weight (>1 MDa) is used for clinical and cosmetic applications [48, 49].

The FTIR spectra of the produced HA (Fig. 4b) was similar to the HA standard (Fig. 4a). The strong band at approximately $3449 \mathrm{~cm}^{-1}$ can be attributed to hydrogen-bonded $\mathrm{O}-\mathrm{H}$ and 
Table 5 Hyaluronic acid production in different fermentation media containing alternative sources

\begin{tabular}{|c|c|c|c|c|}
\hline Bacterial strain & Cultivation conditions & $\begin{array}{l}\text { Carbon and } \\
\text { nitrogen source } \\
\left(\mathrm{g} . \mathrm{L}^{-1}\right)\end{array}$ & $\begin{array}{l}\text { Hyaluronic } \\
\text { acid } \\
\left(\mathrm{g} . \mathrm{L}^{-1}\right)\end{array}$ & Reference \\
\hline $\begin{array}{l}\text { S. zooepidemicus } \\
\text { ATCC } 39920\end{array}$ & $\begin{array}{c}250 \mathrm{~mL} \text { Erlenmeyer; } \\
37^{\circ} \mathrm{C} ; 150 \mathrm{rpm} ; \\
\mathrm{pH} \text { initial } 7.5\end{array}$ & $\begin{array}{l}\text { cashew apple juice ( } 45 \\
\text { of glucose) and yeast } \\
\text { extract (54) }\end{array}$ & 0.89 & {$[11]$} \\
\hline $\begin{array}{l}\text { S. thermophilus } \\
\text { YIT } 2084\end{array}$ & $\begin{array}{l}2 \mathrm{~L} \text { bioreactor, } 40^{\circ} \mathrm{C} ; \\
\text { no aeration; } \\
100 \mathrm{rpm} \text {; } \mathrm{pH} 6.8\end{array}$ & $\begin{array}{l}10 \% \text { of skimmed milk } \\
\text { and soybean peptides } \\
(10)\end{array}$ & 0.21 & {$[43]$} \\
\hline $\begin{array}{l}\text { S. zooepidemicus } \\
\text { ATCC } 35246\end{array}$ & $\begin{array}{l}2 \mathrm{~L} \text { bioreactor; } 37^{\circ} \mathrm{C} ; \\
\text { no aeration; } \\
500 \text { rpm; } \mathrm{pH} 6.7\end{array}$ & $\begin{array}{l}\text { glycogen of mussel } \\
\text { processing wastewater } \\
(50) \text {, tuna peptone } \\
\text { from viscera residue } \\
\text { (protein } 8 \text { ) and yeast } \\
\text { extract (5) }\end{array}$ & 2.46 & {$[14]$} \\
\hline $\begin{array}{l}\text { S. zooepidemicus } \\
\text { ATCC } 39920\end{array}$ & $\begin{array}{l}3 \mathrm{~L} \text { bioreactor; } 37^{\circ} \mathrm{C} \text {; } \\
150 \mathrm{rpm} ; 2 \mathrm{vvm}, \\
\text { pH } 7.0\end{array}$ & $\begin{array}{l}2 \mathrm{~L} \text { cashew apple juice } \\
\text { and yeast extract }(60)\end{array}$ & 1.76 & [19] \\
\hline $\begin{array}{l}\text { S. zooepidemicus } \\
\text { ATCC } 39920\end{array}$ & $\begin{array}{l}125 \mathrm{~mL} \text { Erlenmeyer } \\
\text { flasks; } 37^{\circ} \mathrm{C} ; \\
100 \mathrm{rpm} \mathrm{pH} \text { initial } \\
8.0\end{array}$ & $\begin{array}{l}\text { sugarcane molasses (30) } \\
\text { and yeast extract }(30)\end{array}$ & 0.38 & {$[18]$} \\
\hline $\begin{array}{l}\text { S. zooepidemicus } \\
\text { ATCC } 39920\end{array}$ & $\begin{array}{l}125 \mathrm{~mL} \text { Erlenmeyer } \\
\text { flasks; } 37^{\circ} \mathrm{C} \text {; } \\
100 \mathrm{rpm} \mathrm{pH} \text { initial } \\
8.0\end{array}$ & $\begin{array}{l}\text { sucrose }(30) \text { and soy } \\
\text { protein }(30)\end{array}$ & 0.22 & {$[18]$} \\
\hline $\begin{array}{l}\text { S. zooepidemicus } \\
\text { ATCC } 35246\end{array}$ & $\begin{array}{l}2 \mathrm{~L} \text { bioreactor; } 37^{\circ} \mathrm{C} ; \\
\text { no aeration; } \\
500 \mathrm{rpm} \text {; } \mathrm{pH} 6.7\end{array}$ & $\begin{array}{l}\text { glucose (50), peptones } \\
\text { from alcalase } \\
\text { hydrolyzed viscera } \\
\text { (protein 5) and yeast } \\
\text { extract (5) }\end{array}$ & 2.32 & {$[17]$} \\
\hline $\begin{array}{l}\text { S. zooepidemicus } \\
\text { ATCC } 35246\end{array}$ & $\begin{array}{l}5 \text { L bioreactor; } 37^{\circ} \mathrm{C} ; \\
\text { 1vvm; } 500 \mathrm{rpm} ; \\
\text { pH } 6.7\end{array}$ & $\begin{array}{l}\text { glucose }(50) \text {, lactose }(50) \\
\text { cheese whey (protein } \\
5) \text { and yeast extract (5) }\end{array}$ & 4.0 & {$[20]$} \\
\hline $\begin{array}{l}\text { S. zooepidemicus } \\
\text { ATCC } 39920\end{array}$ & $\begin{array}{l}4.5 \mathrm{~L} \text { bioreactor, } \\
37^{\circ} \mathrm{C} ; 100 \mathrm{rpm} ; \\
0.5 \mathrm{vvm} \text {; pH } 8.0\end{array}$ & $\begin{array}{l}\text { sugarcane molasses } \\
\text { pretreated }(\mathbf{8 5 . 3 5}) \\
\text { and yeast extract }(\mathbf{5 0})\end{array}$ & 2.83 & Present study \\
\hline
\end{tabular}

$\mathrm{N}-\mathrm{H}$ stretching vibrations of the $\mathrm{N}$-acetyl side chain. A group of overlapping bands of moderate intensity is observed at approximately $2922 \mathrm{~cm}^{-1}$ due to the $\mathrm{C}-\mathrm{H}$ stretching vibrations. The bands at 1622 and $1418 \mathrm{~cm}^{-1}$ can be attributed to the asymmetric $(\mathrm{C}=\mathrm{O})$ and symmetric $(\mathrm{C}-\mathrm{O})$ stretching modes of the planar carboxyl groups in the hyaluronate. According to Gilli et al. [50], after protonation, these peaks are shifted to 1735 and $1255 \mathrm{~cm}^{-1}$, respectively. This explained the band at $1738 \mathrm{~cm}^{-1}$ observed in the produced HA. The protonation of the carboxyl group leading to carboxylic acid occurred during the purification process due to the use of trichloroacetic acid. The absorption bands at approximately 1653 , 1564 and $1325 \mathrm{~cm}^{-1}$ are characteristic of the amide I, II and III bands, respectively. The C-O-C group at $1155 \mathrm{~cm}^{-1}$ (O-bridge), C-O (exocyclic) and C-C groups at $1082 \mathrm{~cm}^{-1}$ and the $\mathrm{C}-\mathrm{OH}$ group at $1043 \mathrm{~cm}^{-1}$ are also present [2]. The band at $945 \mathrm{~cm}^{-1}$ can be assigned to an asymmetrical out-of-phase ring vibration [51]. 
Fig. 3 Elution profile of (a) hyaluronic acid standard and (b) hyaluronic acid produced by S. zooepidemicus ATCC 39920 in a bioreactor with controlled $\mathrm{pH}$ analyzed by HPSEC/RID
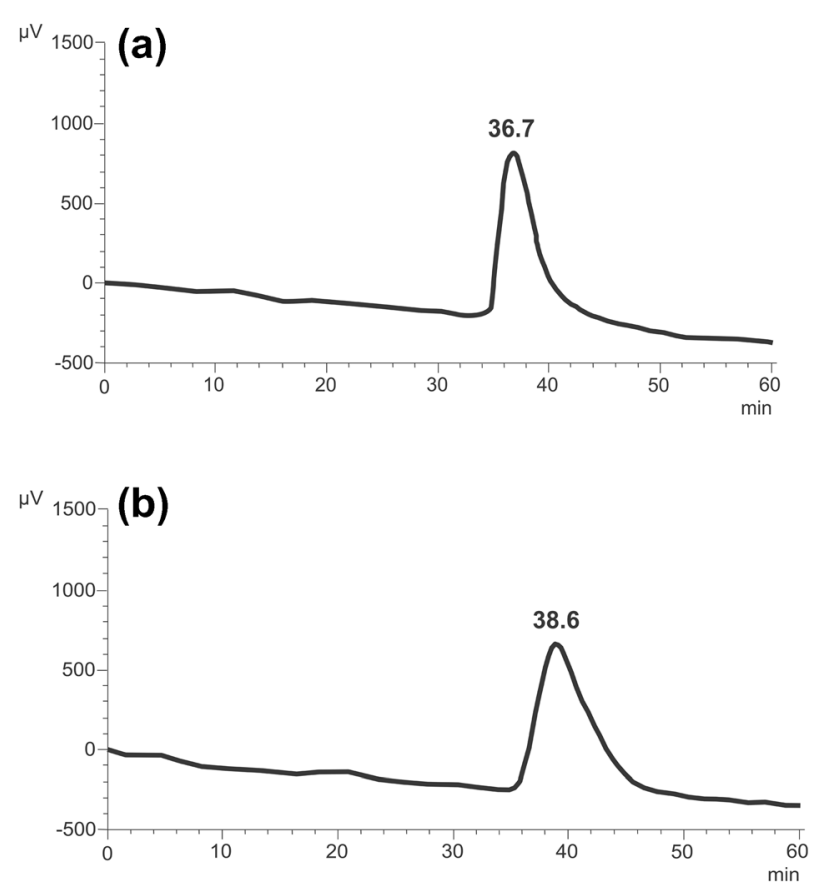

The UV-vis spectra of the standard HA and the HA produced by S. zooepidemicus (Fig. 5) showed that both had the same absorption profile. The maximum absorbance wavelength was $205 \mathrm{~nm}$. Absorbance at $210 \mathrm{~nm}$ was attributed to carboxyl groups [2].

DPPH radical scavenging activity of the produced HA was evident et al.l of the tested concentrations but was lower than that of ascorbic acid (Fig. 6). The highest scavenging effects were $41 \%$ for the produced and standard HA and $84 \%$ for ascorbic acid at $1 \mathrm{~g} . \mathrm{L}^{-1}$. Produced HA showed higher scavenging activity than standard HA at the range of $0.2-0.8$ g.L $\mathrm{L}^{-1}$. This result might be correlated with the lowest molecular weight of the

Fig. 4 FTIR spectra of the (a) hyaluronic acid standard and (b) hyaluronic acid produced by S. zooepidemicus ATCC 39920 in a bioreactor with controlled $\mathrm{pH}$

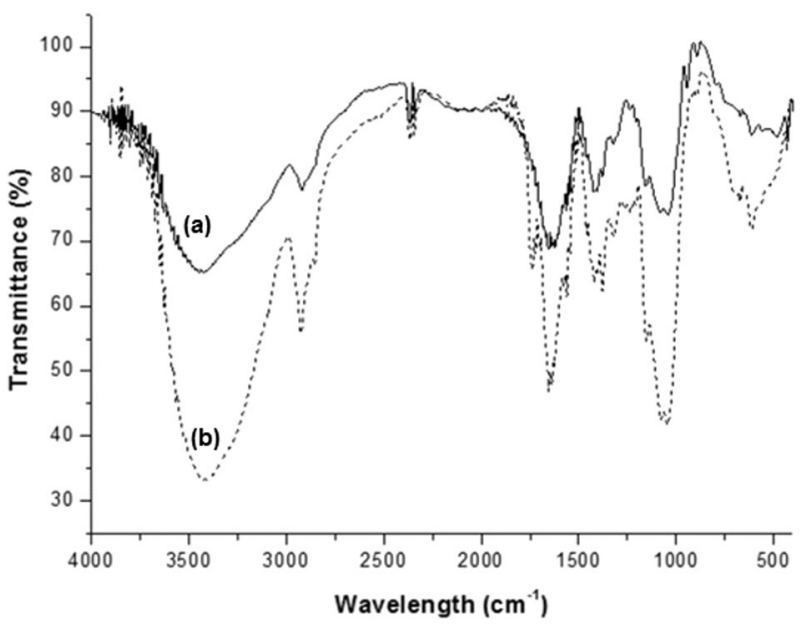




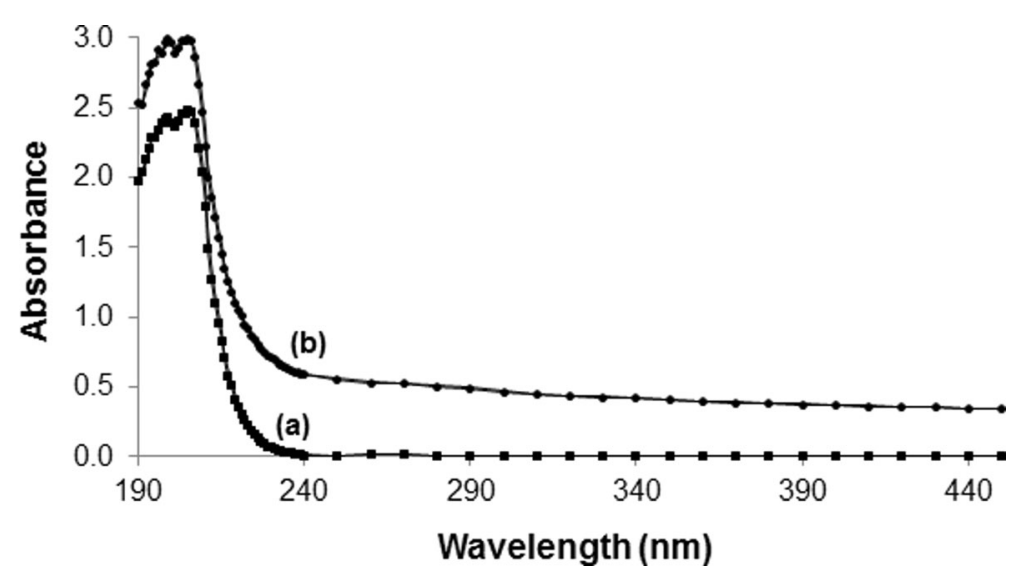

Fig. 5 UV-vis spectrum of the (a) hyaluronic acid standard and (b) hyaluronic acid produced by S. zooepidemicus ATTC 39920 in a bioreactor with controlled $\mathrm{pH}$

produced HA. Several studies showed that polymer antioxidant activity is related to molecular weight [52-54]. Kim et al. [53] showed a gradual increase in DPPH radical scavenging ability of HA by the decreased polymer molecular weight. El-Safory and Lee [52] also observed a stronger radical scavenging activity of HA oligomers than native HA. The mechanism by which HA reduces damage from free radicals is based on its structure, which has cross-linked carboxylic groups. Thus, these carboxylic groups can interact with metal ions such as $\mathrm{Cu}^{2+}$ and $\mathrm{Fe}^{2+}$, allowing these molecules to act as metal chelators [55]. These encouraging results reveal that the HA produced in sugarcane molasses can be employed as a natural antioxidant.

\section{Conclusion}

The present study demonstrated that it is possible to obtain high hyaluronic acid production in an alternative medium using pretreated sugarcane molasses such as carbon source. The

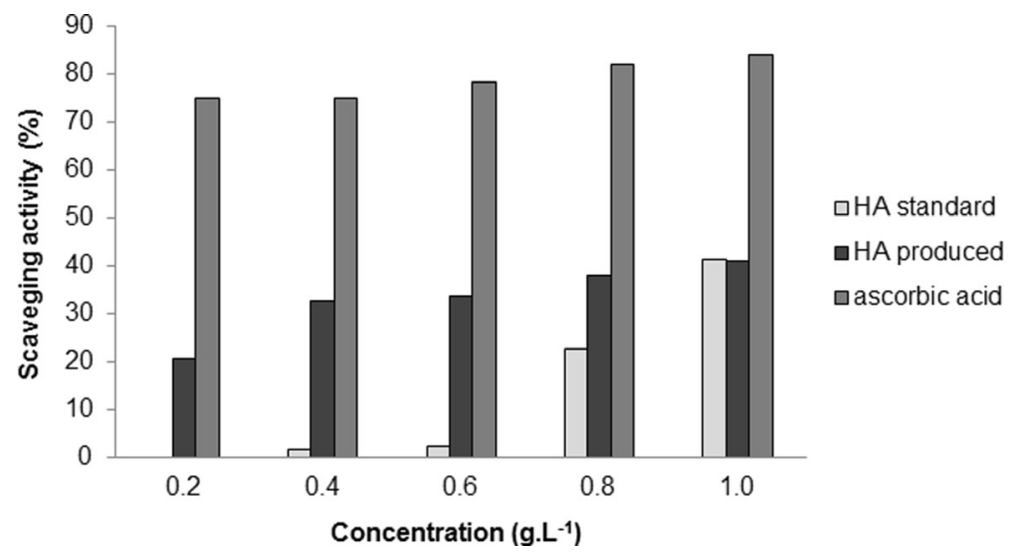

Fig. 6 1,1-Diphenyl-2-picrylhydrazyl (DPPH) radical scavenging activity of the hyaluronic acid standard, hyaluronic acid produced by S. zooepidemicus ATCC 39920 in a bioreactor with controlled pH and ascorbic acid 
maximum HA production was 2.825 g. $\mathrm{L}^{-1}$ at $24 \mathrm{~h}$ in $\mathrm{pH} 8.0$ medium containing pretreated molasses with 85.35 g. $\mathrm{L}^{-1}$ total sugar content and 50 g. $\mathrm{L}^{-1}$ YE in a bioreactor by S. zooepidemicus ATCC 39920. The controlled pH of 8.0 increased the production 2.86-fold. Polymers characterization showed that sugarcane molasses fermentation medium provided an HA appropriate for medical and cosmetic application with $1.35 \times 10^{3} \mathrm{KDa}$ molecular weight and potential antioxidant activity. Thus, pretreated molasses may be an excellent substrate for cost-effective HA production.

Acknowledgements The authors thank Coordination for the Improvement of Higher Education Personnel (CAPES - Brazil) for financial support, Dr. Dionisio Borsato from Londrina State University for support with the statistical analysis, and the Laboratory of Spectroscopy (SPEC) - State University of Londrina for the analyses.

\section{Compliance with Ethical Standards}

Conflict of Interest The authors declare that they have no conflict of interest.

Ethical Statement This article does not contain any studies with human participants or animals performed by any of the authors.

\section{References}

1. Chong, B. F., Blank, L. M., Mclaughlin, R., \& Nielsen, L. K. (2005). Microbial hyaluronic acid production. Applied Microbiology and Biotechnology, 66(4), 341-351.

2. Choi, J., Kim, J.-K., Kim, J.-H., Kweon, D.-K., \& Lee, J.-W. (2010). Degradation of hyaluronic acid powder by electron beam irradiation, gamma ray irradiation, microwave irradiation and thermal treatment: a comparative study. Carbohydrate Polymers, 79(4), 1080-1085.

3. Yu, C.-J., Ko, C.-J., Hsieh, C.-H., Chien, C.-T., Huang, L.-H., Lee, C.-W., \& Jiang, C.-C. (2014). Proteomic analysis of osteoarthritic chondrocyte reveals the hyaluronic acid-regulated proteins involved in chondroprotective effect under oxidative stress. Journal of Proteomics, 99, 40-53.

4. Ong, K. L., Anderson, A. F., Niazi, F., Fierlinger, A. L., Kurtz, S. M., \& Altman, R. D. (2016). Hyaluronic acid injections in medicare knee osteoarthritis patients are associated with longer time to knee arthroplasty. The Journal of Arthroplasty, 31(8), 1667-1673.

5. Kretz, F. T. A., Limberger, I.-J., \& Auffarth, G. U. (2014). Corneal endothelial cell coating during phacoemulsification using a new dispersive hyaluronic acid ophthalmic viscosurgical device. Journal of Cataract and Refractive Surgery, 40(11), 1879-1884.

6. Stead, R. E., Juma, Z., Turner, S., Jones, L. D., \& Sung, V. C. T. (2016). A novel use of reticulated hyaluronic acid (Healaflow) for hypotony eyes in patients with uveitis. British Journal of Ophthalmology, 100(6), 727-730.

7. Su, Z., Ma, H., Wu, Z., Zeng, H., Li, Z., Wang, Y., Liu, G., Xu, B., Lin, Y., Zhang, P., \& Wei, X. (2014). Enhancement of skin wound healing with decellularized scaffolds loaded with hyaluronic acid and epidermal growth factor. Materials Science and Engineering C, 44, 440-448.

8. Wu, Z., Tang, Y., Fang, H., Su, Z., Xu, B., Lin, Y., Zhang, P., \& Wei, X. (2015). Decellularized scaffolds containing hyaluronic acid and EGF for promoting the recovery of skin wounds. Journal of Materials Science: Materials in Medicine, 26(1), 1-10.

9. Wiest, L., \& Kerscher, M. (2008). Native hyaluronic acid in dermatology - results of an expert meeting. Journal der Deutschen Dermatologischen Gesellschaft, 6(3), 176-180.

10. Sundaram, H., Mackiewicz, N., Burton, E., Peno-Mazzarino, L., Lati, E., \& Meunier, S. (2016). Pilot comparative study of the topical action of a novel, crosslinked resilient hyaluronic acid on skin hydration and barrier function in a dynamic, three-dimensional human explant model. Journal of Drugs in Dermatology, 15(4), 434-441. 
11. Pires, A. M. B., Macedo, A. C., Eguchi, S. Y., \& Santana, M. H. A. (2010). Microbial production of hyaluronic acid from agricultural resource derivatives. Bioresource Technology, 101(16), 6506-6509.

12. Yamada, T., \& Kawasaki, T. (2005). Microbial synthesis of hyaluronan and chitin: new approaches. Journal of Bioscience and Bioengineering, 99(6), 521-528.

13. Liu, L., Liu, Y., Li, J., Du, G., \& Chen, J. (2011). Microbial production of hyaluronic acid: current state, challenges, and perspectives. Microbial Cell Factories, 10, 99.

14. Vázquez, J. A., Montemayor, M. I., Fraguas, J., \& Murado, M. A. (2010). Hyaluronic acid production by Streptococcus zooepidemicus in marine by-products media from mussel processing wastewaters and tuna peptone viscera. Microbial Cell Factories, 9, 46.

15. Pires, A. M. B., \& Santana, M. H. A. (2010). Metabolic effects of the initial glucose concentration on microbial production of hyaluronic acid. Applied Biochemistry and Biotechnology, 162(6), 1751-1761.

16. Shah, M. V., Badle, S. S., \& Ramachandran, K. B. (2013). Hyaluronic acid production and molecular weight improvement by redirection of carbon flux towards its biosynthesis pathway. Biochemical Engineering Journal, 80, 53-60.

17. Vázquez, J. A., Pastrana, L., Piñeiro, C., Teixeira, J. A., Pérez-Martín, R. I., \& Amado, I. R. (2015). Production of hyaluronic acid by Streptococcus zooepidemicus on protein substrates obtained from Scyliorhinus canicula discards. Marine Drugs, 13(10), 6537-6549.

18. Pan, N. C., Vignoli, J. A., Baldo, C., Pereira, H. C. B., Silva, R. S. S. F., \& Celligoi, M. A. P. C. (2015). Agroindustrial byproducts for the production of hyaluronic acid by Streptococcus zooepidemicus ATCC 39920. International Journal of Scientific \& Technology Research, 4(04), 114-118.

19. Oliveira, A. H., Ogrodowski, C. C., Macedo, A. C., Santana, M. H. A., \& Gonçalves, L. R. B. (2013). Cashew apple juice as microbial cultivation medium for non-immunogenic hyaluronic acid production. Brazilian Journal of Microbiology, 44(4), 1097-1104.

20. Amado, I. R., Vázquez, J. A., Pastrana, L., \& Teixeira, J. A. (2016). Cheese whey: a cost-effective alternative for hyaluronic acid production by Streptococcus zooepidemicus. Food Chemistry, 198, 54-61.

21. UNICA (2016). Sugarcane, ethanol and sugar production - 2015/2016 harvest season. In Brazilian Sugarcane Industry Association - UNICA. Retrieved May 23, 2016, from http://www.unicadata.com.br

22. Li, H., Jiang, Z., Yang, X., Yu, L., Zhang, G., Wu, J., \& Liu, X. (2015). Sustainable resource opportunity for cane molasses: use of cane molasses as a grinding aid in the production of Portland cement. Journal of Cleaner Production, 93, 56-64.

23. Xu, S., Hao, N., Xu, L., Liu, Z., Yan, M., Li, Y., \& Ouyang, P. (2015). Series fermentation production of ornithine and succinic acid from cane molasses by Corynebacterium glutamicum. Biochemical Engineering Journal, 99, 177-182.

24. Tyagi, N., \& Suresh, S. (2016). Production of cellulose from sugarcane molasses using Gluconacetobacter intermedius SNT-1: optimization \& characterization. Journal of Cleaner Production, 112, 71-80.

25. Ai, H., Liu, M., Yu, P., Zhang, S., Suo, Y., Luo, P., Li, S., \& Wang, J. (2015). Improved welan gum production by Alcaligenes sp. ATCC31555 from pretreated cane molasses. Carbohydrate Polymers, 129, 35-43.

26. Ruiz, S. P., Martinez, C. O., Noce, A. S., Sampaio, A. R., Baesso, M. L., \& Matioli, G. (2015). Biosynthesis of succinoglycan by Agrobacterium radiobacter NBRC 12665 immobilized on loofa sponge and cultivated in sugar cane molasses. Structural and rheological characterization of biopolymer. Journal of Molecular Catalysis B: Enzymatic, 122, 15-28.

27. Oliveira, M. R., Silva, R. S. S. F., Buzato, J. B., \& Celligoi, M. A. P. C. (2007). Study of Levan production by Zymomonas mobilis using regional low-cost carbohydrate sources. Biochemical Engineering Journal, 37(2), 177-183.

28. Treichel, H., Mazutti, M. A., Maugeri Filho, F., \& Rodrigues, M. I. (2009). Technical viability of the production, partial purification and characterisation of inulinase using pretreated agroindustrial residues. Bioprocess and Biosystems Engineering, 32(4), 425-433.

29. Dubois, M., Gilles, K. A., Hamilton, J. K., Rebers, P. A., \& Smith, F. (1956). Colorimetric method for determination of sugars and related substances. Analytical Chemistry, 28(3), 350-356.

30. Pan, N. C., Vignoli, J. A., Baldo, C., Pereira, H. C. B., Silva R. S. dos, S. F., \& Celligoi, M. A. P. C (2015). Effect of fermentation conditions on the production of hyaluronic acid by Streptococcus zooepidemicus ATCC 39920. Acta Scientiarum. Biological Sciences, 37(4), 411-417.

31. Pires, A. M. B., Eguchi, S. Y., \& Santana, M. H. A. (2010). The influence of mineral ions on the microbial production and molecular weight of hyaluronic acid. Applied Biochemistry and Biotechnology, 162(8), 2125-2135.

32. Tlapak-Simmons, V. L., Baron, C. A., \& Weigel, P. H. (2004). Characterization of the purified hyaluronan synthase from Streptococcus equisimilis. Biochemistry, 43(28), 9234-9242.

33. Gomaa, E. Z. (2014). Production of polyhydroxyalkanoates (PHAs) by Bacillus subtilis and Escherichia coli grown on cane molasses fortified with ethanol. Brazilian Archives of Biology and Technology, 57(February), 145-154. 
34. Chong, B. F., \& Nielsen, L. K. (2003). Aerobic cultivation of Streptococcus zooepidemicus and the role of NADH oxidase. Biochemical Engineering Journal, 16(2), 153-162.

35. Armstrong, D. C., \& Johns, M. R. (1997). Culture conditions affect the molecular weight properties of hyaluronic acid produced by Streptococcus zooepidemicus. Applied and Environmental Microbiology, 63(7), 2759-2764.

36. Lai, Z.-W., Rahim, R. A., Ariff, A., \& Mohamad, R. (2011). Medium formulation and impeller design on the biosynthesis of high molecular weight hyaluronic acid by Streptococcus zooepidemicus ATCC 39920. African Journal of Microbiology Research, 5(15), 2114-2123.

37. Im, J.-H., Song, J.-M., Kang, J.-H., \& Kang, D.-J. (2009). Optimization of medium components for highmolecular-weight hyaluronic acid production by Streptococcus $s p$. ID9102 via a statistical approach. Journal of Industrial Microbiology \& Biotechnology, 36(11), 1337-1344.

38. Amrane, A., \& Prigent, Y. (1994). Lactic acid production from lactose in batch culture : analysis of the data with the help of a mathematical model; relevance for nitrogen source and preculture assessment. Applied Microbiology and Biotechnology, 40, 644-649.

39. Haaland, P. D. (1989). Experimental design in biotechnology. (Marcell Dekker, Ed.). NY: CRC Press.

40. Armstrong, D. C., Cooney, M. J., \& Johns, M. R. (1997). Growth and amino acid requirements of hyaluronic-acidproducing Streptococcus zooepidemicus. Applied Microbiology and Biotechnology, 47(3), 309-312.

41. Gao, H.-J., Du, G.-C., \& Chen, J. (2006). Analysis of metabolic fluxes for hyaluronic acid (HA) production by Streptococcus zooepidemicus. World Journal of Microbiology and Biotechnology, 22(4), 399-408.

42. Gamboa-Suasnavart, R. A., Marín-Palacio, L. D., Martínez-Sotelo, J. A., Espitia, C., Servín-González, L., ValdezCruz, N. A., \& Trujillo-Roldán, M. A. (2013). Scale-up from shake flasks to bioreactor, based on power input and Streptomyces lividans morphology, for the production of recombinant APA (45/47 kDa protein) from Mycobacterium tuberculosis. World Journal of Microbiology and Biotechnology, 29(8), 1421-1429.

43. Izawa, N., Hanamizu, T., Sone, T., \& Chiba, K. (2010). Effects of fermentation conditions and soybean peptide supplementation on hyaluronic acid production by Streptococcus thermophilus strain YIT 2084 in milk. Journal of Bioscience and Bioengineering, 109(4), 356-360.

44. Liu, L., Wang, M., Du, G., \& Chen, J. (2008). Enhanced hyaluronic acid production of Streptococcus zooepidemicus by an intermittent alkaline-stress strategy. Letters in Applied Microbiology, 46(3), 383-388.

45. Sun, X., Wang, Z., Bi, Y., Wang, Y., \& Liu, H. (2015). Genetic and functional characterization of the hyaluronate lyase HylB and the Beta-N-Acetylglucosaminidase HylZ in Streptococcus zooepidemicus. Current Microbiology, 70(1), 35-42.

46. Rangaswamy, V., \& Jain, D. (2008). An efficient process for production and purification of hyaluronic acid from Streptococcus equi subsp. zooepidemicus. Biotechnology Letters, 30(3), 493-496.

47. Lai, Z.-W., Rahim, R. A., Ariff, A. B., \& Mohamad, R. (2012). Biosynthesis of high molecular weight hyaluronic acid by Streptococcus zooepidemicus using oxygen vector and optimum impeller tip speed. Journal of Bioscience and Bioengineering, 114(3), 286-291.

48. Jeong, E., Shim, W. Y., \& Kim, J. H. (2014). Metabolic engineering of Pichia pastoris for production of hyaluronic acid with high molecular weight. Journal of Biotechnology, 185, 28-36.

49. Guillaumie, F., Furrer, P., Felt-Baeyens, O., Fuhlendorff, B. L., Nymand, S., Westh, P., Gurny, R., \& Schwach-Abdellaoui, K. (2010). Comparative studies of various hyaluronic acids produced by microbial fermentation for potential topical ophthalmic applications. Journal of Biomedical Materials Research - Part A, 92(4), 1421-1430.

50. Gilli, R., Kacuráková, M., Mathlouthi, M., Navarini, L., \& Paoletti, S. (1994). FTIR studies of sodium hyaluronate and its oligomers in the amorphous solid phase and in aqueous solution. Carbohydrate Research, 263(2), 315-326.

51. Wu, Y. (2012). Preparation of low-molecular-weight hyaluronic acid by ozone treatment. Carbohydrate Polymers, 89(2), 709-712.

52. El-Safory, N. S., \& Lee, C.-K. (2010). Cytotoxic and antioxidant effects of unsaturated hyaluronic acid oligomers. Carbohydrate Polymers, 82(4), 1116-1123.

53. Kim, J. K., Srinivasan, P., Kim, J. H., Choi, J., Park, H. J., Byun, M. W., \& Lee, J. W. (2008). Structural and antioxidant properties of gamma irradiated hyaluronic acid. Food Chemistry, 109(4), 763-770.

54. Ke, C., Sun, L., Qiao, D., Wang, D., \& Zeng, X. (2011). Antioxidant acitivity of low molecular weight hyaluronic acid. Food and Chemical Toxicology, 49(10), 2670-2675.

55. Campo, G. M., Avenoso, A., Campo, S., D’Ascola, A., Ferlazzo, A. M., \& Calatroni, A. (2004). The antioxidant and antifibrogenic effects of the glycosaminoglycans hyaluronic acid and chondroitin-4-sulphate in a subchronic rat model of carbon tetrachloride-induced liver fibrogenesis. Chemico-Biological Interactions, 148(3), 125-138. 